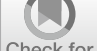

Check for

updates

Cite as

Nano-Micro Lett.

(2020) 12:133

Received: 25 March 2020

Accepted: 10 April 2020

Published online: 19 June 2020

(C) The Author(s) 2020

\title{
Bismuth-Based Free-Standing Electrodes for Ambient-Condition Ammonia Production in Neutral Media
}

Ying Sun ${ }^{1,2}$, Zizhao Deng ${ }^{1}$, Xi-Ming Song ${ }^{3}$, Hui Li ${ }^{1}$, Zihang Huang ${ }^{1}$, Qin Zhao ${ }^{1}$, Daming Feng ${ }^{1}$, Wei Zhang ${ }^{3}$, Zhaoqing Liu ${ }^{4}$, Tianyi $\mathrm{Ma}^{2} \bowtie$

$\triangle$ Tianyi Ma,Tianyi.Ma@newcastle.edu.au

1 Institute of Clean Energy Chemistry, Key Laboratory for Green Synthesis and Preparative Chemistry of Advanced Materials, College of Chemistry, Liaoning University, Shenyang 110036, People's Republic of China

2 Discipline of Chemistry, University of Newcastle, Callaghan, NSW 2308, Australia

3 Key Laboratory for Green Synthesis and Preparative Chemistry of Advanced Materials, College of Chemistry, Liaoning University, Shenyang 110036, People's Republic of China

4 School of Chemistry and Chemical Engineering, Guangzhou Key Laboratory for Environmentally Functional Materials and Technology, Guangzhou University, Guangzhou 510006, People's Republic of China

\section{HIGHLIGHTS}

- The $\mathrm{Bi}_{2} \mathrm{O}_{3}$ nanoplates homogeneously decorated free-standing exfoliated graphene $\left(\mathrm{Bi}_{2} \mathrm{O}_{3} / \mathrm{FEG}\right)$ was prepared by a facile electrochemical deposition method.

- The $\mathrm{Bi}_{2} \mathrm{O}_{3} /$ FEG first used as nitrogen reduction electrocatalyst exhibits excellent electrocatalysis performance and stability for nitrogen reduction reaction in neutral media.

- The superior electrocatalytic nitrogen reduction activity is attributed to the strong interaction of the Bi $6 p$ band with the $\mathrm{N} 2 p$ orbitals, binder-free nature of the electrodes, and facile electron transfer through the graphene nanosheets.

\begin{abstract}
Electrocatalytic nitrogen reduction reaction is a carbonfree and energy-saving strategy for efficient synthesis of ammonia under ambient conditions. Here, we report the synthesis of nanosized $\mathrm{Bi}_{2} \mathrm{O}_{3}$ particles grown on functionalized exfoliated graphene $\left(\mathrm{Bi}_{2} \mathrm{O}_{3} / \mathrm{FEG}\right)$ via a facile electrochemical deposition method. The obtained free-standing $\mathrm{Bi}_{2} \mathrm{O}_{3} / \mathrm{FEG}$ achieves a high Faradaic efficiency of $11.2 \%$ and a large $\mathrm{NH}_{3}$ yield of $4.21 \pm 0.14 \mu \mathrm{g}_{\mathrm{NH}_{3}} \mathrm{~h}^{-1} \mathrm{~cm}^{-2}$ at $-0.5 \mathrm{~V}$ versus reversible hydrogen electrode in $0.1 \mathrm{M} \mathrm{Na}_{2} \mathrm{SO}_{4}$, better than that in the strong acidic and basic media. Benefiting from its strong interaction of $\mathrm{Bi} 6 p$ band with the $\mathrm{N} 2 p$ orbitals, binder-free characteristic, and facile electron transfer, $\mathrm{Bi}_{2} \mathrm{O}_{3} / \mathrm{FEG}$ achieves superior catalytic performance and excellent long-term stability as compared with most of the previous reported catalysts. This study is significant to design low-cost, high-efficient Bi-based electrocatalysts for electrochemical ammonia synthesis.
\end{abstract}

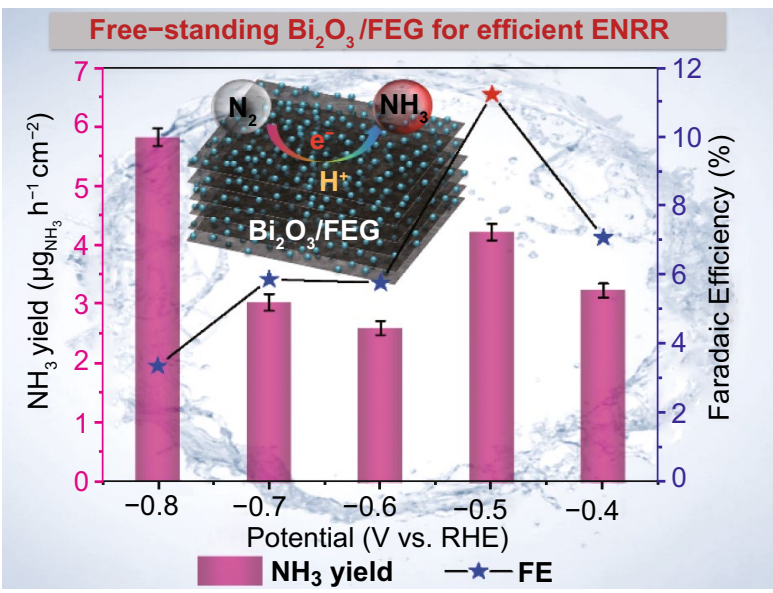

KEYWORDS $\mathrm{N}_{2}$ reduction; $\mathrm{Bi}_{2} \mathrm{O}_{3}$ nanoplate; Electrocatalysis; Free-standing 


\section{Introduction}

Ammonia $\left(\mathrm{NH}_{3}\right)$ is considered to be a promising hydrogen energy carrier to alleviate the fossil fuel shortage and global climate change, for its high energy density, high hydrogen content, no carbon footprint and being easy to liquefy [1-3]. To date, the dominant method for industrial-scale $\mathrm{NH}_{3}$ synthesis still depends on the traditional Haber-Bosch process [4-6]. However, this energy-intensive and environmentally hazardous process consumes $2 \%$ of the global annual energy and leads to $1 \%$ of the world's $\mathrm{CO}_{2}$ emission [7]. It is thus imperative to develop sustainable and economical techniques for $\mathrm{NH}_{3}$ synthesis at mild conditions.

The electrochemical nitrogen reduction reaction (ENRR) is regarded as an energy-saving and carbon-free process, which can synthesize $\mathrm{NH}_{3}$ at ambient conditions by utilizing renewable energy such as those from wind and solar [8-12]. Unfortunately, the scaled-up application of the ENRR process is seriously hampered by the low ammonia yields and Faraday efficiency due to the extremely weak $\mathrm{N}_{2}$ adsorption, the low solubility of $\mathrm{N}_{2}$ in aqueous electrolytes, and the sluggish cleavage of the $\mathrm{N} \equiv \mathrm{N}$ bond [13]. Over the past 5 years, numerous metal-based materials, including metal [7, 14-18], metal oxides [19-21], metal sulfides [22, 23], metal nitrides [24], etc., have been developed as electrocatalysts for ENRR. Most of the above metal-based catalysts involving the metallic centers of $\mathrm{Au}$ [7], $\mathrm{Ru}$ [17], Ni [20], Mo [18, 22], etc., exhibited favorable activity for ENRR by elaborately designing the particle size, crystallinity, heteroatom doping, and/ or vacancies. Despite the substantial progress, the ENRR still suffers from the major competitive hydrogen evolution reaction (HER). Therefore, the rational design of the active catalytic centers of efficient ENRR electrocatalysts that can efficiently reduce the large activation barrier of $\mathrm{N} \equiv \mathrm{N}$, accelerate its dissociation and most importantly suppress HER, is still a highly challenging but vitally important issue [25].

Bismuth-based catalysts are considered to be promising candidates for efficient ENRR in recent years [26-30]. Bi as a main group element with tunable $p$-electron density and intrinsic less reactive nature can selectively promote the reductive adsorption of $\mathrm{N}_{2}$ to form $\mathrm{N}_{2} \mathrm{H}^{*}$ without influencing the binding energy of the later intermediates, and also restrict the surface electron accessibility for effectively suppressing the competitive HER process [26-28]. Yan et al. demonstrated that overlaping of the $\mathrm{Bi} 6 p$ bands and the
$2 p$ orbitals of the $\mathrm{N}$ atom both below and above the Fermi level can offer a lower free-energy change for the potentialdetermining step and better ENRR activity than typical transition metal catalysts [29]. Most of the Bi-based electrocatalysts for ENRR reported previously are mainly focused on the metallic bismuth $\left(\mathrm{Bi}^{0}\right)$ [27-29]. It was reported that both the defect-rich Bi and 2D mosaic Bi nanosheets have been used for ENRR, and offered excellent selectivity in $0.2 \mathrm{M} \mathrm{Na}_{2} \mathrm{SO}_{4}$ (Faradaic efficiency (FE): $11.68 \%$ at $-0.6 \mathrm{~V}$ vs. RHE) [28] and $0.1 \mathrm{M}^{\text {in }} \mathrm{Na}_{2} \mathrm{SO}_{4}$ (FE: $10.46 \pm 1.45 \%$ at $-0.8 \mathrm{~V}$ vs. RHE) [31], respectively. As an abundant Bibased material, $\mathrm{Bi}_{2} \mathrm{O}_{3}$ has received much attention in photocatalysis due to its unique electrical and optical properties [32-34]. It was also used as a precursor for the synthesis of other Bi-based materials [28]. However, bismuth oxide has hardly been reported for ENRR, with part of reason being that the semiconducting $\mathrm{Bi}_{2} \mathrm{O}_{3}$ shows poor charge transport, while the easy aggregation of $\mathrm{Bi}_{2} \mathrm{O}_{3}$ instead of nanosized status largely impairs the adsorption and reactivity to $\mathrm{N}_{2}$. Therefore, a robust support is necessary to enhance the conductivity, at the same time offer well dispersion of the $\mathrm{Bi}_{2} \mathrm{O}_{3}$ nanoparticles.

Functionalized exfoliated graphene (FEG) acts as an ideal 3D-conductive scaffold for supporting catalysts, which is constructed by ultrathin partially oxidized graphene nanosheets anchoring on the graphite substrate [35-37]. The FEG modified by oxygen-containing groups $(-\mathrm{OH},-\mathrm{COOH})$ that provide active defect sites, can act as an excellent substrate for metal oxides deposition when using the metal ions as the precursor [38]. It is the high surface area and excellent electron conductivity of graphene nanosheets that can accelerate the charge transport and keep credible electric contact, resulting in the enormously improved catalytic efficiency [39-42]. In addition, polymer binder (e.g., Nafion) is widely used for attaching the electrocatalysts to the collectors, which seriously hampers the mass transport and obstructs the charge transmission, and therefore reduces the overall catalytic performance of the electrocatalysts [43, 44]. Therefore, the in situ growth of metal oxides on FEG with highly exposed active sites, superior electron conductivity, and large surface area is vitally important to improve the electrocatalytic performance. Based on the above analysis results, it is reasonable to assume that the composite electrocatalysts composed of well-coupled $\mathrm{Bi}_{2} \mathrm{O}_{3}$ and FEG can act as a promising candidate to promote the electrochemical reduction of $\mathrm{N}_{2}$ to $\mathrm{NH}_{3}$. 
Herein, we developed a new type of ENRR catalyst by immobilizing $\mathrm{Bi}_{2} \mathrm{O}_{3}$ nanoplates onto the surface of FEG, to form the free-standing hybrid material $\left(\mathrm{Bi}_{2} \mathrm{O}_{3} / \mathrm{FEG}\right)$, which was then directly used as an electrode for ENRR in different electrolytes under ambient conditions. In this ENRR system, the competitive hydrogen evolution reaction (HER) is expected to be suppressed by the better intrinsic ENRR activity of Bi. Moreover, the highly conductive FEG was utilized to compensate for the semiconducting property of $\mathrm{Bi}_{2} \mathrm{O}_{3}$ and eliminate its aggregation. The as-prepared $\mathrm{Bi}_{2} \mathrm{O}_{3} /$ FEG catalyst exhibits high ENRR activity with a high $\mathrm{NH}_{3}$ yield rate of $4.21 \pm 0.14 \mu_{\mathrm{NH}_{3}} \mathrm{~h}^{-1} \mathrm{~cm}^{-2}$, and a favorable $\mathrm{FE}$ as high as $11.2 \%$ at $-0.5 \mathrm{~V}$ versus RHE in $0.1 \mathrm{M} \mathrm{Na}_{2} \mathrm{SO}_{4}$ electrolyte, out-performing most reported ENRR catalysts.

\section{Experimental}

\subsection{Synthesis of the Functionalized Exfoliated Graphene (FEG)}

The FEG substrate was prepared through an electrochemical exfoliation method according to our previous work with slight modification [45]. The exfoliation process was performed in a typical three-electrode cell using the graphite foil [GF, the exposed surface area is $1 \times 1 \mathrm{~cm}^{2}$ (length $\times$ width)] as the working electrode, a platinum plate and a saturated calomel electrode (SCE) as the counter and reference electrodes, respectively. First, the GF was scanned between 0.5 and $1.7 \mathrm{~V}$ (vs. SCE) using cyclic voltammetry at $15 \mathrm{mV} \mathrm{s}^{-1}$ in $0.5 \mathrm{M} \mathrm{K}_{2} \mathrm{CO}_{3}$ electrolyte for ten cycles. Subsequently, the electrode was further treated at a constant potential of $1.8 \mathrm{~V}$ (vs. SCE) for $2 \mathrm{~h}$ in $0.5 \mathrm{M} \mathrm{KNO}_{3}$ aqueous solution to generate functional groups. Then, the electrode was potential dynamically scanned between -1.0 and $0.9 \mathrm{~V}$ (vs. SCE) at $50 \mathrm{mV} \mathrm{s}^{-1}$ for 50 cycles in $3 \mathrm{M} \mathrm{KCl}$ electrolyte to recover the electrical conductivity. Finally, the FEG substrate was rinsed with deionized water and ethanol to remove the residuals.

\subsection{Synthesis of the nanosized $\mathrm{Bi}_{2} \mathrm{O}_{3}$ Modified FEG $\left(\mathrm{Bi}_{2} \mathrm{O}_{3} / \mathrm{FEG}\right)$}

$\mathrm{Bi}_{2} \mathrm{O}_{3} /$ FEG was synthesized through an electrochemical deposition process. $0.3 \mathrm{~g}$ of bismuth chloride $\left(\mathrm{BiCl}_{3}\right)$ was dissolved into $25 \mathrm{~mL}$ ethylene glycol (EG) and stirred at
$25{ }^{\circ} \mathrm{C}$ for $1 \mathrm{~h}$ forming the electrolyte. The electrodeposition process was conducted in a two-electrode cell with a platinum plate as the counter electrode and a piece of FEG $\left(1 \times 1 \mathrm{~cm}^{2}\right)$ as the working electrode. $\mathrm{Bi}_{2} \mathrm{O}_{3}$ nanoparticles were electrodeposited on FEG at a constant current density of $1 \mathrm{~mA} \mathrm{~cm}{ }^{-2}$ at ambient temperature for $5 \mathrm{~min}$. The assynthesized product was washed with tetrahydrofuran and ethanol and subsequently dried in a vacuum oven at $70{ }^{\circ} \mathrm{C}$ for $12 \mathrm{~h}$, finally obtaining free-standing $\mathrm{Bi}_{2} \mathrm{O}_{3} /$ FEG.

\subsection{Electrocatalytic ENRR Measurements}

Before ENRR tests, the Nafion 117 membrane was cut into small pieces and then treated with $3 \mathrm{wt} \% \mathrm{H}_{2} \mathrm{O}_{2}$ water solution, deionized water, $1 \mathrm{~mol} \mathrm{~L}^{-1} \mathrm{H}_{2} \mathrm{SO}_{4}$ and deionized water for $1 \mathrm{~h}$ at $80{ }^{\circ} \mathrm{C}$, respectively. Finally, the obtained membrane was repeatedly rinsed until neutral $\mathrm{pH}$ was obtained and then was preserved in deionized water. Electrochemical measurements were performed in an airtight two-compartment cell at ambient conditions using an electrochemical workstation (CHI 760E), with $\mathrm{Bi}_{2} \mathrm{O}_{3} /$ FEG or FEG as the working electrode, $\mathrm{Pt}$ foil as the counter electrode, and $\mathrm{Ag} /$ $\mathrm{AgCl}$ (filled with $3.5 \mathrm{M} \mathrm{KCl}$ solution) as the reference electrode. The potentials were converted to reversible hydrogen electrode (RHE) scale via calibration with the Nernst equation $\left(E_{\mathrm{RHE}}=E_{\mathrm{Ag} / \mathrm{AgCl}}+0.059 \mathrm{pH}+0.205 \mathrm{~V}\right)$. The linear sweep voltammetry (LSV) curves were collected in $0.1 \mathrm{M}$ $\mathrm{Na}_{2} \mathrm{SO}_{4}$ electrolyte saturated with ultrahigh $\mathrm{Ar}$ or $\mathrm{N}_{2}$ for $30 \mathrm{~min}$ at a sweep rate of $5 \mathrm{mV} \mathrm{s}^{-1}$, respectively.

\subsection{Determination of Ammonia}

The concentrations of the synthesized $\mathrm{NH}_{3}$ in the electrolyte were measured by a colorimetric method using Nessler's reagent as the color reagent. For this method, $10 \mathrm{~mL}$ electrolyte was mixed with $0.2 \mathrm{~mL} 50 \%$ seignette salt solution. Then $0.2 \mathrm{~mL}$ Nessler's reagent was added and the mixture was allowed still for $10 \mathrm{~min}$. Then the mixture was detected as the absorbance at $420 \mathrm{~nm}$ by a UV-Vis spectrometer (Shimadzu UV-2600). A standard curve of the Nessler's reagentbased colorimetric method is constructed by measuring a series of absorbances for the reference solution with different $\mathrm{NH}_{4} \mathrm{Cl}$ concentrations $(0.00,0.10,0.20,0.30,0.40$, and $\left.0.50 \mu \mathrm{g} \mathrm{mL}^{-1}\right)$. The background is corrected with a blank solution (as shown in Fig. S1). 
An ion-selective electrode meter (Orion Star A214 Benchtop $\mathrm{pH} / \mathrm{ISE}$ Meter; Thermo Scientific) for $\mathrm{NH}_{3}$ detection was also performed to further verify the reliability of the colorimetric method. The details were according to our previous work [46] (as shown in Supporting Infromation).

\subsection{Determination of Hydrazine}

The yield of hydrazine in the electrolyte was evaluated via Watt and Chrisp method. The hydrazine chromogenic reagent is a mixture of para-(dimethylamino) benzaldehyde $(0.599 \mathrm{~g})$, ethanol $(300 \mathrm{~mL})$ and concentrated $\mathrm{HCl}(30 \mathrm{~mL})$. After $2 \mathrm{~h}$ ENRR reaction, $2 \mathrm{~mL}$ of the above reagent was added into $2 \mathrm{~mL}$ of the electrolyte and then the mixture was detected at $460 \mathrm{~nm}$. The concentration-absorbance curve was calibrated using standard hydrazine hydrate solution with a serious of concentrations $\left(Y=2.225 X+0.03, R^{2}=0.99913\right)$ (as shown in Fig. S2).

\subsection{Calculation of Faradaic Efficiency (FE) and $\mathrm{NH}_{3}$ Yield Rate}

The FE for $\mathrm{NH}_{3}$ production and $\mathrm{NH}_{3}$ yield rate were calculated at an applied potential as follow (Eqs. 1 and 2):

$\mathrm{FE}_{\mathrm{NH}_{3}}=C_{\mathrm{NH}_{3}} \times V \times 3 F / Q$

$\mathrm{NH}_{3}$ yield rate $=C_{\mathrm{NH}_{3}} \times V /(t \times m)$

where $C_{\mathrm{NH} 3}$ is the concentration of $\mathrm{NH}_{3}, V$ is the volume of the electrolyte, $F$ is the Faraday constant of $96,485 \mathrm{C} \mathrm{mol}^{-1}$, $Q$ is the total charge passed through the electrochemical system, $t$ is the reaction time of ENRR process, and $m$ is the mass of the catalytic active site, i.e., the $\mathrm{Bi}$ atoms of $\mathrm{Bi}_{2} \mathrm{O}_{3}$ molecule on the surface of the $\mathrm{Bi}_{2} \mathrm{O}_{3} / \mathrm{FEG}$ electrode.

\subsection{Calculation of Equilibrium Potential}

At the very beginning of the ENRR, the newly produced ammonia formed a type of coordination with water, as shown in Eq. 3:

$\mathrm{N}_{2}(g)+2 \mathrm{H}_{2} \mathrm{O}(l)+6 \mathrm{H}^{+}$(aq.) $+6 e^{-} \rightleftharpoons 2 \mathrm{NH}_{3} \cdot \mathrm{H}_{2} \mathrm{O}$ (aq.)

The equilibrium potential for ENRR under our experimental conditions is calculated using the Nernst equation as shown in Eq. 4, assuming 1 atm of $\mathrm{N}_{2}$ and an $\mathrm{NH}_{3} \cdot \mathrm{H}_{2} \mathrm{O}$ concentration of $0.5 \times 10^{-5} \mathrm{M}$ in the solution [46].

$$
\begin{aligned}
E & =E^{\mathrm{o}}-\frac{R T}{n F} \ln \left(\frac{\left[\mathrm{NH}_{3} \cdot \mathrm{H}_{2} \mathrm{O}\right]^{2}}{\left[\mathrm{H}^{+}\right]^{6}}\right)+0.059 \mathrm{~V} \times \mathrm{pH} \\
& =0.196 \mathrm{~V}(\text { vs. } \mathrm{RHE})
\end{aligned}
$$

where $E^{0}=0.092 \mathrm{~V}$ is the standard potential for the above half reaction of ENRR, $R=8.314 \mathrm{~J} \mathrm{~mol}^{-1} \mathrm{~K}^{-1}$ is the molar gas constant, $n=6$ is the number of electrons transferred in Eq. 3, $F=96,485 \mathrm{C} \mathrm{mol}^{-1}$ is the Faraday constant, $T=298.15 \mathrm{~K}$ is the reaction temperature in this experimental condition.

\section{Results and Discussion}

\subsection{Materials Characterization}

Scheme 1 illustrates the synthesis procedure to obtain the free-standing $\mathrm{Bi}_{2} \mathrm{O}_{3} / \mathrm{FEG}$ hybrid. Typically, the FEG substrate was prepared through electrochemical exfoliating the graphite foil into functionalized exfoliated graphene nanosheets with abundant oxygen functional groups. Sequentially, the $\mathrm{Bi}_{2} \mathrm{O}_{3}$ nanoplates were uniformly immobilized onto the $\mathrm{FEG}$ with $\mathrm{BiCl}_{3}$ as the precursor through a facile electrochemical deposition method, during which

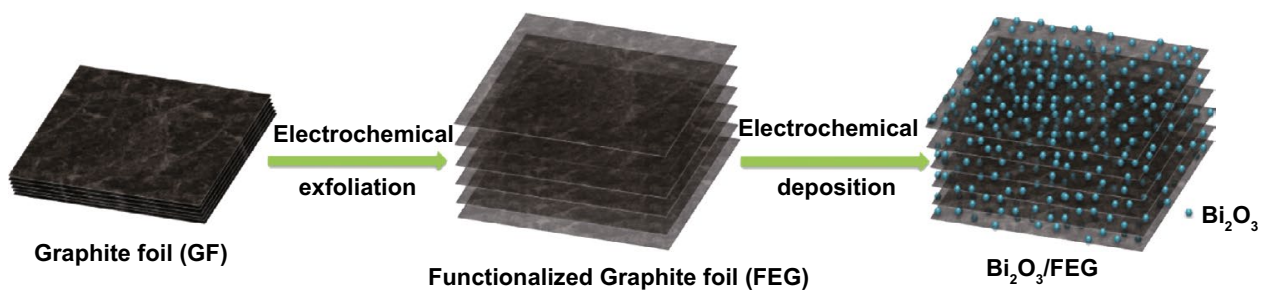

Scheme 1 Illustration of the synthesis of $\mathrm{Bi}_{2} \mathrm{O}_{3} /$ FEG 
the mass loading and the morphology of the $\mathrm{Bi}_{2} \mathrm{O}_{3}$ can be easily controlled by adjusting the electrolyte concentration and deposition duration. The actual weight of $\mathrm{Bi}$ in $\mathrm{Bi}_{2} \mathrm{O}_{3} /$ FEG electrodes was determined to be approximately $0.74 \mathrm{mg} \mathrm{cm}^{-2}$ by measuring the weight before and after the electrodeposition process, followed by ICP-AES confirmation.

The morphology and microstructure of as-prepared $\mathrm{Bi}_{2} \mathrm{O}_{3} /$ FEG were investigated by scanning electron microscopy (SEM) and transmission electron microscopy (TEM). Figure 1a shows the SEM images of the as-prepared $\mathrm{Bi}_{2} \mathrm{O}_{3} / \mathrm{FEG}$ hybrid. It can be clearly observed that, after electrochemical deposition, $\mathrm{Bi}_{2} \mathrm{O}_{3}$ nanoplates are uniformly grown on the surface of the loosely packed FEG layers. This is due to the fact that oxygen functional groups in graphene nanosheets play a structure-directing role in the electrochemical deposition. The $\mathrm{Bi}^{3+}$ precursors can be captured through coordination bonding with the hydroxyl and carboxyl groups in graphene nanosheets, which were introduced in the electrochemical exfoliation process [38]. Then this uniform deposition of $\mathrm{Bi}_{2} \mathrm{O}_{3}$ in the nanosheets of FEG can be achieved by the following electrochemical process. The SEM and corresponding elemental $(\mathrm{Bi}, \mathrm{C}$, and $\mathrm{O})$ mapping images of $\mathrm{Bi}_{2} \mathrm{O}_{3} / \mathrm{FEG}$ are shown in Fig. 1b. Uniform distribution of bismuth (from $\mathrm{Bi}_{2} \mathrm{O}_{3}$ nanoplates) combined with the carbon and oxygen can be detected over the whole area of the $\mathrm{Bi}_{2} \mathrm{O}_{3} / \mathrm{FEG}$ nanosheet, further demonstrating the presence of homogeneous $\mathrm{Bi}_{2} \mathrm{O}_{3}$ nanoplates on the graphene sheet of FEG. The transmission electron microscopy (TEM) of the as-prepared $\mathrm{Bi}_{2} \mathrm{O}_{3} /$ FEG hybrid is shown in Fig. 1c, which further confirms the $\mathrm{Bi}_{2} \mathrm{O}_{3}$ nanoplates with a particle size of about $5 \mathrm{~nm}$ evenly decorated on the graphene nanosheets of FEG. The TEM image of $\mathrm{Bi}_{2} \mathrm{O}_{3} / \mathrm{FEG}$ in Fig. 1c (inset) further displays that numerous $\mathrm{Bi}_{2} \mathrm{O}_{3}$ nanoplates are homogeneously dispersed on the surface of FEG. As shown in Fig. 1c, the high-resolution TEM (HRTEM) image of $\mathrm{Bi}_{2} \mathrm{O}_{3} /$ FEG hybrid reveals the uniform distributed $\mathrm{Bi}_{2} \mathrm{O}_{3}$ on the surface of FEG with well-defined nanocrystalline nature. The magnification corresponding HRTEM images in the circle area of Fig. 1c reveal the lattice fringes of $0.25 \mathrm{~nm}$ (Fig. 1d), which could be well indexed to the (102) plane of $\mathrm{Bi}_{2} \mathrm{O}_{3}$. The selected area electron diffraction (SAED) pattern indicates the monocrystalline nature of $\mathrm{Bi}_{2} \mathrm{O}_{3}$ nanoplates and reveals the (102), (100), and (002) planes of $\mathrm{Bi}_{2} \mathrm{O}_{3}$ (inset of Fig. 1d), further confirming the existence of $\mathrm{Bi}_{2} \mathrm{O}_{3}$ in FEG.
X-ray diffraction (XRD) patterns of pure FEG and the as-prepared $\mathrm{Bi}_{2} \mathrm{O}_{3} /$ FEG hybrid are displayed in Fig. S3. The strong peak at $26.3^{\circ}$ of FEG is indexed to the (002) plane of graphene [36] that confirms the successful synthesis of pure FEG. It is found that $\mathrm{Bi}_{2} \mathrm{O}_{3} / \mathrm{FEG}$ hybrid also exhibited a characteristic peak of graphene at $26.6^{\circ}$. This intense and sharp peak indicates highly crystalline graphene nature of $\mathrm{Bi}_{2} \mathrm{O}_{3} / \mathrm{FEG}$, which is beneficial to the electron transfer. No characteristic diffraction peaks of $\mathrm{Bi}_{2} \mathrm{O}_{3}$ are observed because of its lower loading content. This also implies the good dispersion of the very small $\mathrm{Bi}_{2} \mathrm{O}_{3}$ particles on the FEG.

The full-range X-ray photoelectron spectroscopy (XPS) spectra of FEG and the as-prepared $\mathrm{Bi}_{2} \mathrm{O}_{3} /$ FEG hybrid are shown in Fig. 1e, and it was observed that two peaks appeared at 285.6 and $532.0 \mathrm{eV}$, corresponding to the $\mathrm{C} 1 \mathrm{~s}$ and $\mathrm{O} 1 s$ core level spectrum, respectively. Moreover, the presence of Bi electrons was confirmed by the XPS analysis of $\mathrm{Bi}_{2} \mathrm{O}_{3} /$ FEG, the three doublet peaks at around 690.0, 455.0 , and $162.0 \mathrm{eV}$, corresponding to the $\mathrm{Bi} 4 p, \mathrm{Bi} 4 d$, and Bi $4 f$ electrons, indicating that some $\mathrm{Bi}_{2} \mathrm{O}_{3}$ was immobilized on the FEG. In the high-solution Bi $4 f$ XPS spectrum (Fig. 1f), two main peaks centered at 159.8 and $165.1 \mathrm{eV}$ can be identified as $\mathrm{Bi} 4 f_{7 / 2}$ and $\mathrm{Bi} 4 f_{5 / 2}$ signals of $\mathrm{Bi}^{3+}$, respectively, in accordance with previous reports [47]. And the $0.8 \mathrm{eV}$ blueshift of $\mathrm{Bi} 4 f_{7 / 2}$ and $\mathrm{Bi} 4 f_{5 / 2}$ peaks due to charge transfer from $\mathrm{Bi}^{3+}$ center to the FEG. The results from the above characterizations demonstrate that FEG is an excellent substrate for the deposition and fixation of $\mathrm{Bi}_{2} \mathrm{O}_{3}$ nanoplates. The incorporation of $\mathrm{Bi}_{2} \mathrm{O}_{3}$ nanoplates into the FEG prevented the aggregation of $\mathrm{Bi}_{2} \mathrm{O}_{3}$ nanoplates and provided more reactive sites, that may improve its performance of ENRR.

The contact angle measurement was then performed to investigate the hydrophilicity of $\mathrm{FEG}$ and $\mathrm{Bi}_{2} \mathrm{O}_{3} / \mathrm{FEG}$. It can be seen from Fig. S4a, the surface of FEG whose contact angle is approximately $83^{\circ}$ exhibits strong hydrophilicity, which is mainly due to the oxygen functional groups ( $-\mathrm{OOH}$ and -OH) of FEG. After decorated with $\mathrm{Bi}_{2} \mathrm{O}_{3}$, the contact angle of the as-prepared $\mathrm{Bi}_{2} \mathrm{O}_{3} / \mathrm{FEG}$ increases to around $110^{\circ}$ (Fig. S4b), indicating a hydrophobic property. This hydrophobicity is expected to be helpful in promoting the ENRR performance by providing strong interaction with $\mathrm{N}_{2}$ gas [48]. 

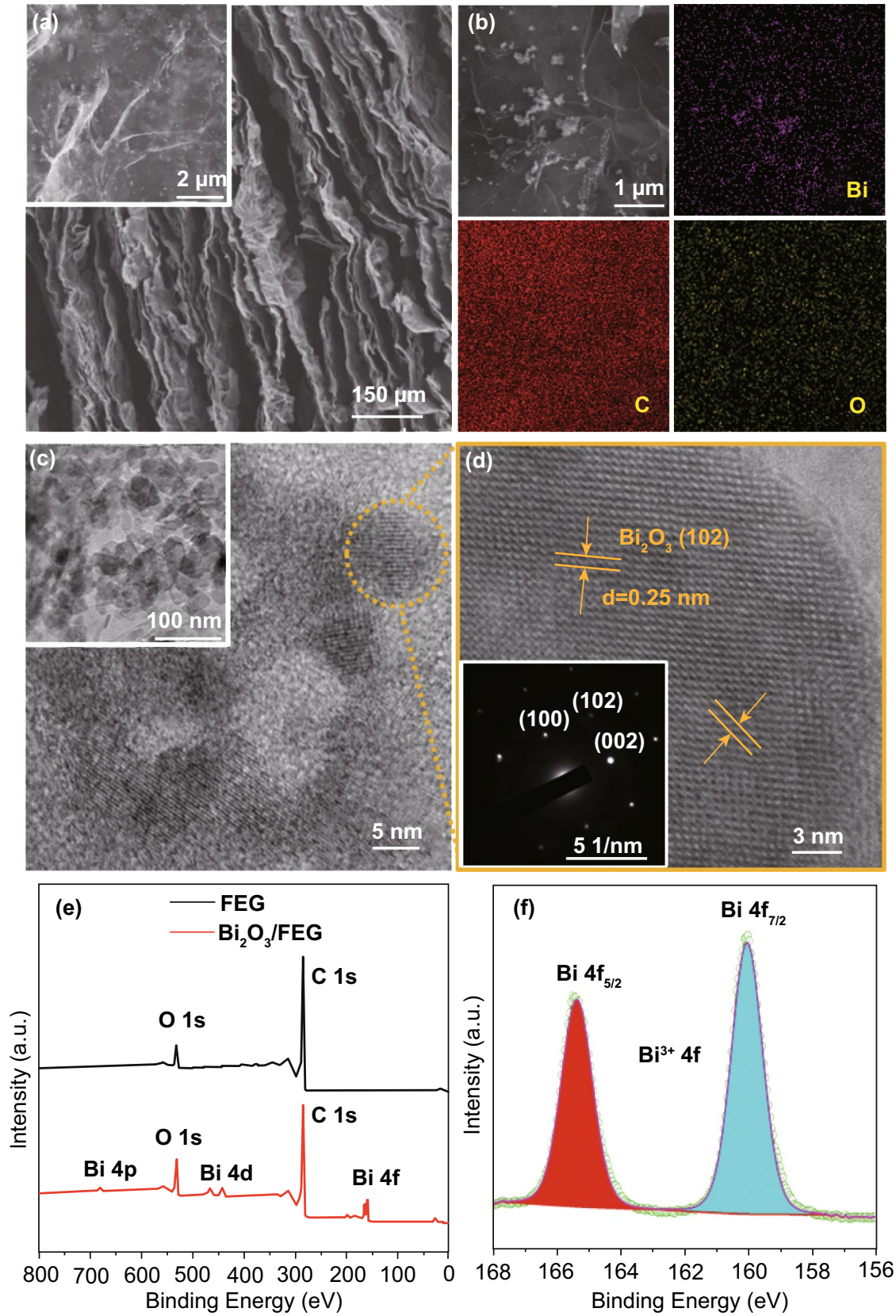

Fig. 1 a SEM images of $\mathrm{Bi}_{2} \mathrm{O}_{3} / \mathrm{FEG}$ with the inset showing the high-magnification SEM image. b SEM and corresponding elemental (Bi, C, and $\mathrm{O}$ ) mapping images of $\mathrm{Bi}_{2} \mathrm{O}_{3}$ /FEG. $\mathbf{c}$ HRTEM images of $\mathrm{Bi}_{2} \mathrm{O}_{3} / F E G$, the inset shows the TEM image. d Corresponding HRTEM images in the circle area, the inset shows the SAED pattern. e XPS spectra of $\mathrm{Bi}_{2} \mathrm{O}_{3} / \mathrm{FEG}$ and the FEG substrate; inset is the magnified image. $\mathrm{f}$ Bi $4 f$ XPS spectrum of $\mathrm{Bi}_{2} \mathrm{O}_{3} / \mathrm{FEG}$

\subsection{Electrochemical Nitrogen Reduction}

The ENRR performance of the prepared $\mathrm{Bi}_{2} \mathrm{O}_{3} /$ FEG catalyst was evaluated in $\mathrm{N}_{2}$-saturated $0.1 \mathrm{M} \mathrm{Na}_{2} \mathrm{SO}_{4}$ electrolyte under ambient conditions using a two-compartment electrochemical cell, separated by a Nafion 117 membrane. The free-standing $\mathrm{Bi}_{2} \mathrm{O}_{3} /$ FEG hybrid material was directly used as the working electrode, with a platinum plate as the 
counter electrode and $\mathrm{Ag} / \mathrm{AgCl}$ as the reference electrode (configuration shown in Fig. 2a). The feeding gas (ultrahigh purity $\mathrm{N}_{2}, 99.999 \%$ ) was continuously bubbled into the cathode via a bubbler during the experiment at the flow rate of $10 \mathrm{~mL} \mathrm{~min}{ }^{-1}$. All potentials were reported on a reversible hydrogen electrode (RHE) scale. First, we studied the potential dependence of ENRR activity of $\mathrm{Bi}_{2} \mathrm{O}_{3} / \mathrm{FEG}$ by LSV in Ar- and $\mathrm{N}_{2}$-saturated $0.1 \mathrm{M} \mathrm{Na}_{2} \mathrm{SO}_{4}$ electrolytes at a scan rate of $5 \mathrm{mV} \mathrm{s}^{-1}$. As shown in Fig. S5, the LSV curves of $\mathrm{Bi}_{2} \mathrm{O}_{3} / \mathrm{FEG}$ in $\mathrm{Ar}$ and $\mathrm{N}_{2}$-saturated electrolytes exhibit the same shape, but a higher current density is achieved in the $\mathrm{N}_{2}$-saturated electrolyte when potential is more negative than $-0.4 \mathrm{~V}$, implying that $\mathrm{Bi}_{2} \mathrm{O}_{3} / \mathrm{FEG}$ possesses catalytic activity for ENRR reaction.

Further, chronoamperometry tests at a series of potentials were carried out to explore the catalytic activity and identify the optimal potential of the $\mathrm{Bi}_{2} \mathrm{O}_{3} / \mathrm{FEG}$ electrode for the ENRR (Fig. 2b). The concentration of the produced

(a)
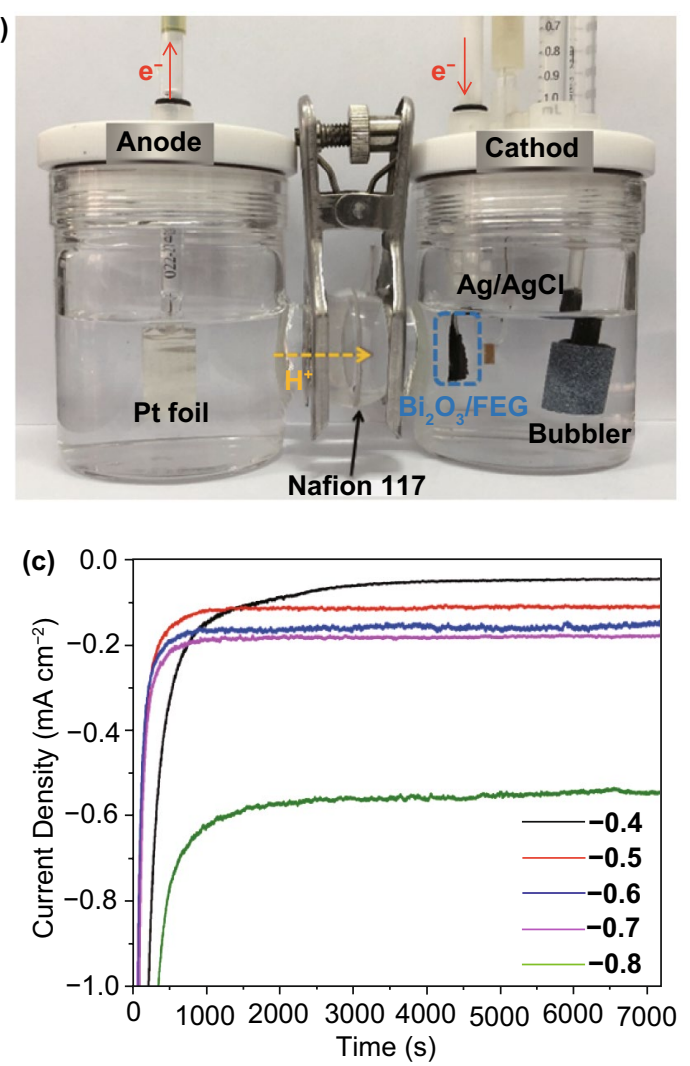

ammonia in solution after the 2 h electrolysis was determined independently by a spectrophotometry method with Nessler's reagent as a color reagent, while the possible $\mathrm{N}_{2} \mathrm{H}_{4}$ by-product was detected by a spectrophotometry method with $p-\mathrm{C}_{9} \mathrm{H}_{11} \mathrm{NO}$ as an indicator.

The average ammonia yields and the corresponding FE of $\mathrm{Bi}_{2} \mathrm{O}_{3} / \mathrm{FEG}$ at potentials from -0.4 to $-0.8 \mathrm{~V}$ (vs. RHE) in $0.1 \mathrm{M} \mathrm{Na}_{2} \mathrm{SO}_{4}$ are plotted in Fig. 2b. The FE value at $-0.4 \mathrm{~V}$ (vs. RHE) is $7.1 \%$, and then the ENRR rate and FE rise with the negative potential increasing until $-0.5 \mathrm{~V}$ (vs. RHE), where the relatively high $\mathrm{NH}_{3}$ yield and the maximum FE value can reach $4.21 \pm 0.14 \mu \mathrm{g}_{\mathrm{NH}_{3}} \mathrm{~h}^{-1} \mathrm{~cm}^{-2}$ (i.e., $5.68 \mu \mathrm{g}_{\mathrm{NH}_{3}} \mathrm{mg}_{\mathrm{Bi}}^{-1} \mathrm{~h}^{-1}$ ) and $11.2 \%$, respectively. No $\mathrm{N}_{2} \mathrm{H}_{4}$ byproduct has been detected, indicating the good selectivity of the $\mathrm{Bi}_{2} \mathrm{O}_{3} / \mathrm{FEG}$ catalyst for ENRR. Meanwhile, ENRR was also conducted on FEG in $\mathrm{N}_{2}$-saturated $0.1 \mathrm{M} \mathrm{Na}_{2} \mathrm{SO}_{4}$ solution at $-0.5 \mathrm{~V}$ (vs. RHE) to verify the source of $\mathrm{NH}_{3}$. No $\mathrm{NH}_{3}$ was detected, indicating that FEG had no catalytic
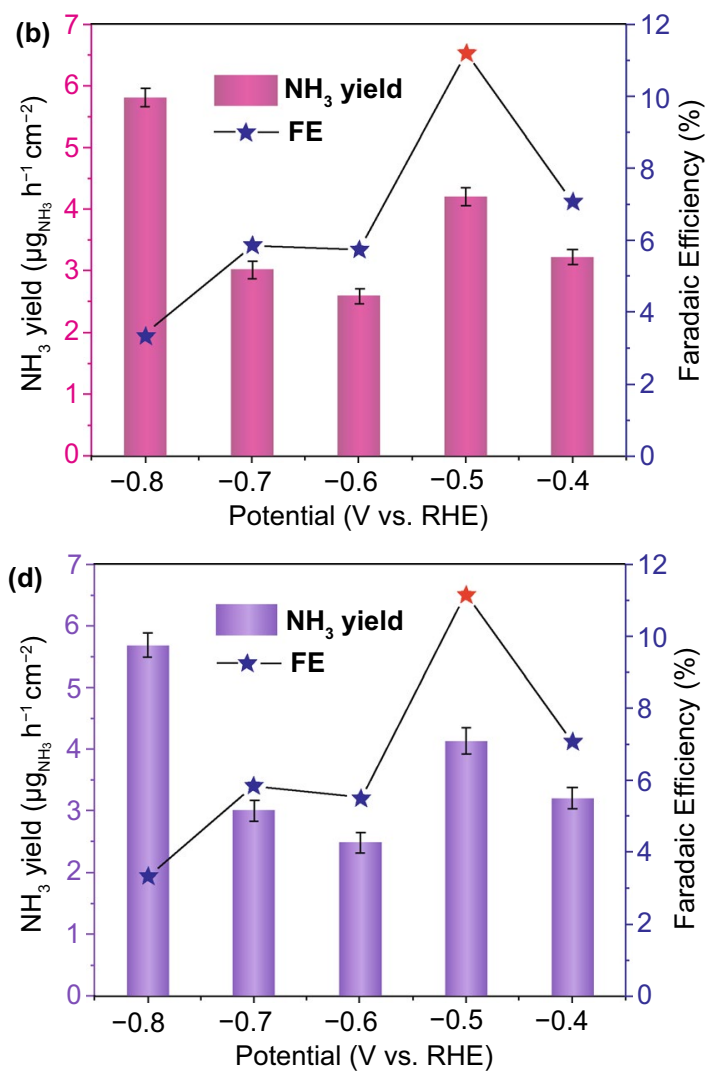

Fig. 2 a Schematic reaction cell for ENRR. b Faradic efficiency and $\mathrm{NH}_{3}$ yield rate at various potentials in $0.1 \mathrm{M} \mathrm{Na}_{2} \mathrm{SO}_{4}$ electrolyte (determined by the Nessler's reagent). $\mathbf{c}$ Chronoamperometry results at the corresponding potentials. $\mathbf{d} \mathrm{FE}$ and $\mathrm{NH}_{3}$ yield rate at various potentials in $0.1 \mathrm{M} \mathrm{Na}_{2} \mathrm{SO}_{4}$ electrolyte (determined by ion-selective electrode meter) 
activity toward ENRR for the production of $\mathrm{NH}_{3}$, and the contribution of $\mathrm{NH}_{3}$ yield from the impurities of FEG was also negligible. Therefore, it can be inferred here that the $\mathrm{Bi}_{2} \mathrm{O}_{3}$ in $\mathrm{Bi}_{2} \mathrm{O}_{3} /$ FEG played a decisive role in the ENRR, while FEG possessed no activity toward the ENRR.

This ENRR catalytic performance of the as-prepared $\mathrm{Bi}_{2} \mathrm{O}_{3} /$ FEG hybrid material can even comparable to the yields and efficiencies catalyzed by metal-based nanocatalysts as shown in Table S1. For example, Bi nanosheets (FE of $10.46 \%$ with an $\mathrm{NH}_{3}$ yield rate of $2.54 \mu \mathrm{g} \mathrm{h}^{-1} \mathrm{~cm}^{-2}$ at $-0.8 \mathrm{~V}$ (vs. RHE) in $0.1 \mathrm{M} \mathrm{Na}_{2} \mathrm{SO}_{4}$ electrolyte) [31] and $\mathrm{Au}$ nanorod (FE of $4.02 \%$ with an $\mathrm{NH}_{3}$ yield rate of $1.648 \mu \mathrm{g} \mathrm{h}^{-1} \mathrm{~cm}^{-2}$ at $-0.2 \mathrm{~V}$ vs. RHE in $0.1 \mathrm{M} \mathrm{KOH}$ electrolyte) [49]. The excellent ENRR performance of the as-prepared $\mathrm{Bi}_{2} \mathrm{O}_{3} / \mathrm{FEG}$ hybrid material is mainly due to the following reasons. On the one hand, this high ENRR activity is primarily attributed to the $\mathrm{Bi}$ center from $\mathrm{Bi}_{2} \mathrm{O}_{3}$, which can effectively inhibit the side reaction of HER during ENRR process by binding ${ }^{*} \mathrm{~N}_{2} \mathrm{H}$ more strongly without affecting the binding energy of ${ }^{*} \mathrm{NH}_{2}$ or ${ }^{*} \mathrm{NH}[26,31]$, and offer a lower free-energy change than traditional transition mental for a better ENRR activity [29]. On the other hand, the nanosized $\mathrm{Bi}_{2} \mathrm{O}_{3}$ and the large surface of FEG, which provide abundant active sites, may insure the efficient ENRR reaction. Besides, the facile electron and mass transfer process from the graphene nanosheets of $\mathrm{Bi}_{2} \mathrm{O}_{3} /$ FEG accelerate the ENRR process through promoting the electron transport, and the hydrophobic property of $\mathrm{Bi}_{2} \mathrm{O}_{3} /$ FEG provides strong interaction with $\mathrm{N}_{2}$ gas further accelerate the ENRR.

In addition, as shown in Fig. 2c, the current density at different potentials behaves good stability, which can be attributed to the well dispersion and anchoring of the nanosized $\mathrm{Bi}_{2} \mathrm{O}_{3}$ nanoplates on the graphene nanosheets. Unexpectedly, though the $\mathrm{NH}_{3}$ yield reaches the highest average value of $5.8 \pm 0.15 \mu \mathrm{g}_{\mathrm{NH}_{3}} \mathrm{~h}^{-1} \mathrm{~cm}^{-2}$ at $-0.8 \mathrm{~V}$ (vs. RHE), the FE values decrease obviously when the applied potentials are more negative than $-0.5 \mathrm{~V}$ (vs. RHE). A plausible explanation is that the ENRR in this system was in a $\mathrm{N}_{2}$ diffusion-controlled mode, and the feeding gas $\mathrm{N}_{2}$ has extremely low solubility in aqueous electrolyte. At higher negative potentials, the competing reaction (HER) was dominant [46], so the surface of $\mathrm{Bi}_{2} \mathrm{O}_{3} / F E G$ was mainly occupied by the hydrogen molecules which would impede the mass transfer of $\mathrm{N}_{2}$ to the surface of $\mathrm{Bi}_{2} \mathrm{O}_{3}$ / FEG, and thus strongly reduce the ENRR selectivity.
The concentrations of the $\mathrm{NH}_{3}$ synthesized by $\mathrm{Bi}_{2} \mathrm{O}_{3} /$ FEG at potentials from -0.4 to $-0.8 \mathrm{~V}$ (vs. RHE) in $0.1 \mathrm{M} \mathrm{Na}_{2} \mathrm{SO}_{4}$ were also determined by ion-selective electrode meter to confirm the reliability of this colorimetric method for ammonia detection. As shown in Fig. 2d, the corresponding average $\mathrm{NH}_{3}$ yields and FE were almost identical to that of determined by the Nessler's reagent (Fig. 2b) within experimental error, suggesting that it was reliable to use the Nessler's reagent for the quantitative analysis of the produced $\mathrm{NH}_{3}$.

Subsequently, chronoamperometry tests in $\mathrm{N}_{2}$-saturated $0.1 \mathrm{M} \mathrm{KOH}$ or $0.05 \mathrm{M} \mathrm{H}_{2} \mathrm{SO}_{4}$ electrolyte under the same experimental conditions as that of in $\mathrm{Na}_{2} \mathrm{SO}_{4}$ electrolyte were carried out to explore the catalytic activity of the $\mathrm{Bi}_{2} \mathrm{O}_{3} / \mathrm{FEG}$ in strong basic and acidic media. As shown in Fig. 3a, the optimum average $\mathrm{NH}_{3}$ yield rate $3.07 \pm 0.11 \mu \mathrm{g}_{\mathrm{NH}_{3}} \mathrm{~h}^{-1} \mathrm{~cm}^{-2}$ in thestrong basic electrolyte occurred at $-0.5 \mathrm{~V}$ (vs. RHE), indicating a wide $\mathrm{pH}$ response of $\mathrm{Bi}_{2} \mathrm{O}_{3} /$ FEG. However, the relatively low $\mathrm{FE}$ of $0.59 \%$ may be caused by the high current density implying dominant HER (Fig. S7). Furthermore, the robust current stability of $\mathrm{Bi}_{2} \mathrm{O}_{3} / \mathrm{FEG}$ in $0.1 \mathrm{M} \mathrm{KOH}$ has been confirmed for $2 \mathrm{~h}$ electrolysis, as shown in Fig. 3b, indicating ideal stability of $\mathrm{Bi}_{2} \mathrm{O}_{3} /$ FEG in the strong basic electrolyte. The $\mathrm{NH}_{3}$ yields and the corresponding $\mathrm{FE}$ of $\mathrm{Bi}_{2} \mathrm{O}_{3} / \mathrm{FEG}$ at potentials from -0.2 to $-0.6 \mathrm{~V}$ (vs. RHE) in $0.05 \mathrm{M} \mathrm{H}_{2} \mathrm{SO}_{4}$ are plotted in Fig. 3c. The $\mathrm{NH}_{3}$ yield at $-0.2 \mathrm{~V}$ (vs. RHE) is $2.8 \mu \mathrm{g}_{\mathrm{NH}_{3}} \mathrm{~h}^{-1} \mathrm{~cm}^{-2}$ with the FE of $1.36 \%$, then the NRR rate and FE decrease sharply with the potential shifted negatively. The dissatisfactory catalytic performance in $0.05 \mathrm{M} \mathrm{Na}_{2} \mathrm{SO}_{4}$ electrolyte should attribute to the instability of $\mathrm{Bi}_{2} \mathrm{O}_{3}$ and the drastic HER competing reaction in acid medium. Comparing the optimum $\mathrm{FE}$ and $\mathrm{NH}_{3}$ yield rates of $\mathrm{Bi}_{2} \mathrm{O}_{3} / \mathrm{FEG}$ in different electrolytes as shown in Fig. 3d, $\mathrm{Bi}_{2} \mathrm{O}_{3} /$ FEG exhibits excellent electrocatalysis performance and stability for ENRR in neutral media even better than that in strong basic and acidic media under the same ambient conditions. It is highly desired to develop electrocatalysts for efficient and durable ENRR catalysis at neutral conditions, which is beneficial for alleviating the serious environment sufferings, reducing equipment and catalyst corrosions, lower the cost of the whole ENRR process, and further accelerating the practical applications of ENRR.

The stability of the $\mathrm{Bi}_{2} \mathrm{O}_{3} / \mathrm{FEG}$ was evaluated by consecutive recycling electrolysis and long-term 

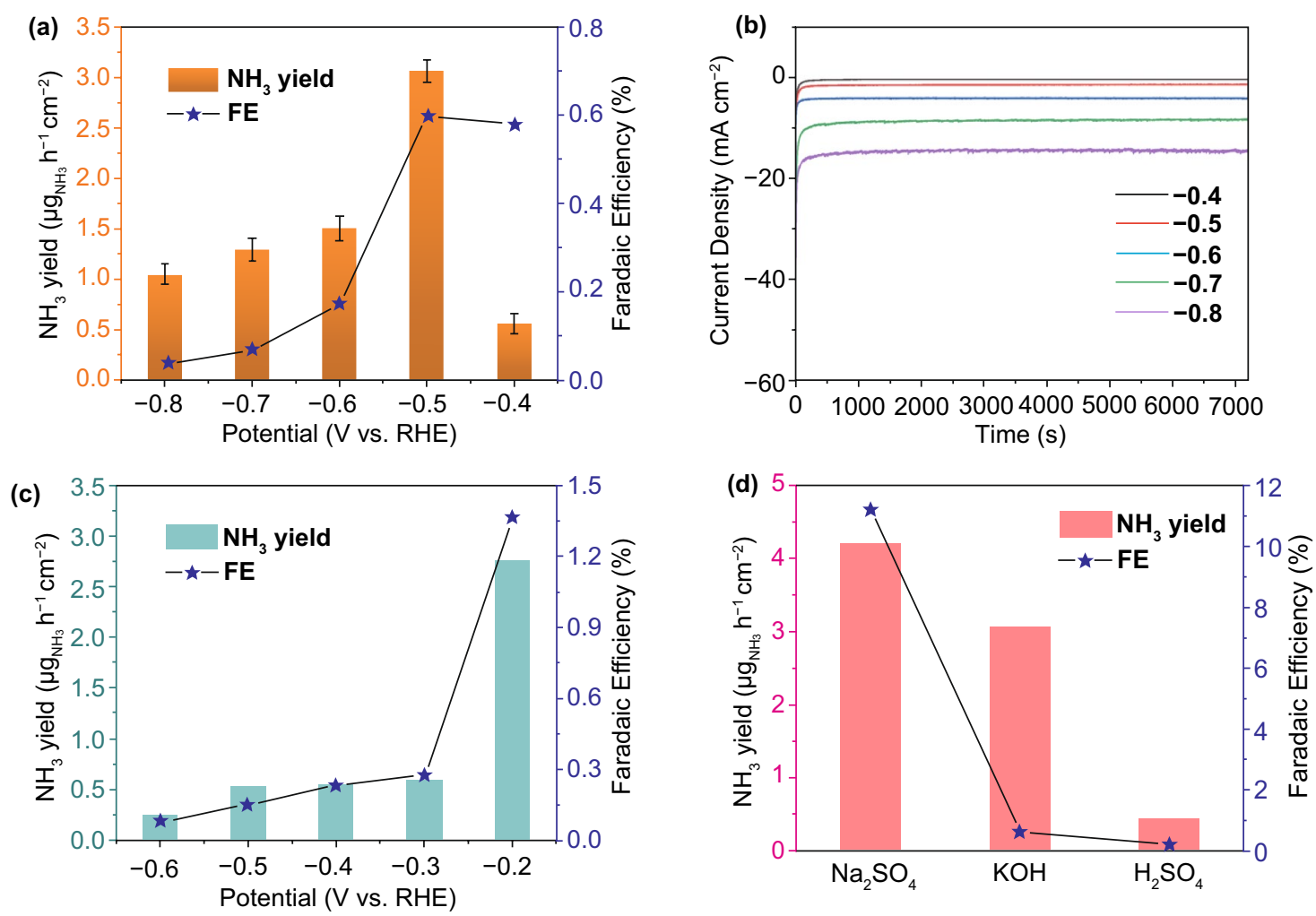

Fig. 3 a $\mathrm{FE}$ and $\mathrm{NH}_{3}$ yield rate at various potentials in $0.1 \mathrm{M} \mathrm{KOH}$ electrolyte (determined by the Nessler's reagent). b Chronoamperometry results at the corresponding potentials. c FE and $\mathrm{NH}_{3}$ yield rate at various potentials in $0.05 \mathrm{M} \mathrm{H}_{2} \mathrm{SO}_{4}$ electrolyte (determined by the Nessler's reagent). d Optimum $\mathrm{FE}$ and yield rates of $\mathrm{NH}_{3}$ in different electrolytes (at $-0.5 \mathrm{~V}$ vs. RHE, determined by the Nessler's reagent)

chronoamperometry test at $-0.5 \mathrm{~V}$ (vs. RHE) in $0.1 \mathrm{M}$ $\mathrm{Na}_{2} \mathrm{SO}_{4}$. As shown in Fig. $4 \mathrm{a}$, no obvious change in the $\mathrm{NH}_{3}$ yield and Faradaic efficiency could be observed during five consecutive recycling electrolysis, which suggests the excellent stability of $\mathrm{Bi}_{2} \mathrm{O}_{3} / \mathrm{FEG}$ for $\mathrm{NH}_{3}$ synthesis at ambient conditions. In addition, slight degradation of current density in the process of long-term chronoamperometry test is detected for $12 \mathrm{~h}$ at $-0.5 \mathrm{~V}$ (vs. RHE) (Fig. 4b). Moreover, no obvious variation of the $\mathrm{NH}_{3}$ yield rate and FE could be observed after $12 \mathrm{~h}$ long-term chronoamperometry test, indicating the high robustness of $\mathrm{Bi}_{2} \mathrm{O}_{3} /$ FEG toward ambient $\mathrm{NH}_{3}$ synthesis. Furthermore, both the compositions and $\mathrm{Bi}_{2} \mathrm{O}_{3}$ nature of the $\mathrm{Bi}_{2} \mathrm{O}_{3} / F E G$ could be well maintained after the long-term electrocatalysis reaction when comparing TEM images (Fig. 4c) and XPS (Fig. 4d) before and after the reaction. All these observations demonstrate the excellent electrochemical durability of the $\mathrm{Bi}_{2} \mathrm{O}_{3} / \mathrm{FEG}$ for the ENRR, which is another crucial factor for the enhancement of ENRR performances.

\section{Conclusions}

In summary, a highly efficient hybrid ENRR electrocatalyst composed of nanosized $\mathrm{Bi}_{2} \mathrm{O}_{3}$ supported on FEG was developed. Due to the synergistic effect between the nanosized $\mathrm{Bi}_{2} \mathrm{O}_{3}$ and the large surface area of FEG, the $\mathrm{Bi}_{2} \mathrm{O}_{3} / \mathrm{FEG}$ hybrid exhibited the superb electrocatalytic performance toward ENRR at a low overpotential of $-0.5 \mathrm{~V}$ (vs. RHE) in the neutral electrolyte and under ambient temperature and pressure. The $\mathrm{FE}$ of $\mathrm{Bi}_{2} \mathrm{O}_{3} / \mathrm{FEG}$ in $0.1 \mathrm{M} \mathrm{Na}_{2} \mathrm{SO}_{4}$ electrolyte is $11.2 \%$ with the $\mathrm{NH}_{3}$ yields of $5.68 \mu \mathrm{g}_{\mathrm{NH}_{3}} \mathrm{mg}_{\mathrm{Bi}}^{-1} \mathrm{~h}^{-1}$, which is superior to that of most state-of-the-art ENRR electrocatalysts reported up to date. The high ENRR activity is attributed to the $\mathrm{Bi}$ center from $\mathrm{Bi}_{2} \mathrm{O}_{3}$ during the ENRR process with the help of the facile electron transfer process from the graphene nanosheets of FEG. This work opens an avenue to rational designing of Bi-based carbon hybrid electrocatalysts and highlights the catalytic center engineering strategy to effectively manipulate the catalytic performance of electrocatalysts. 

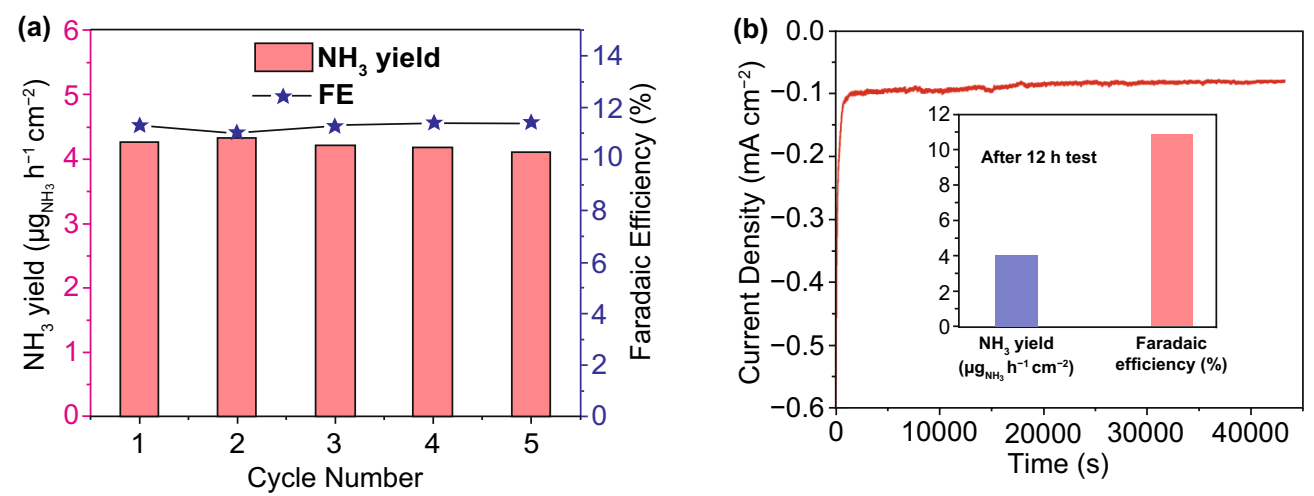

(c)
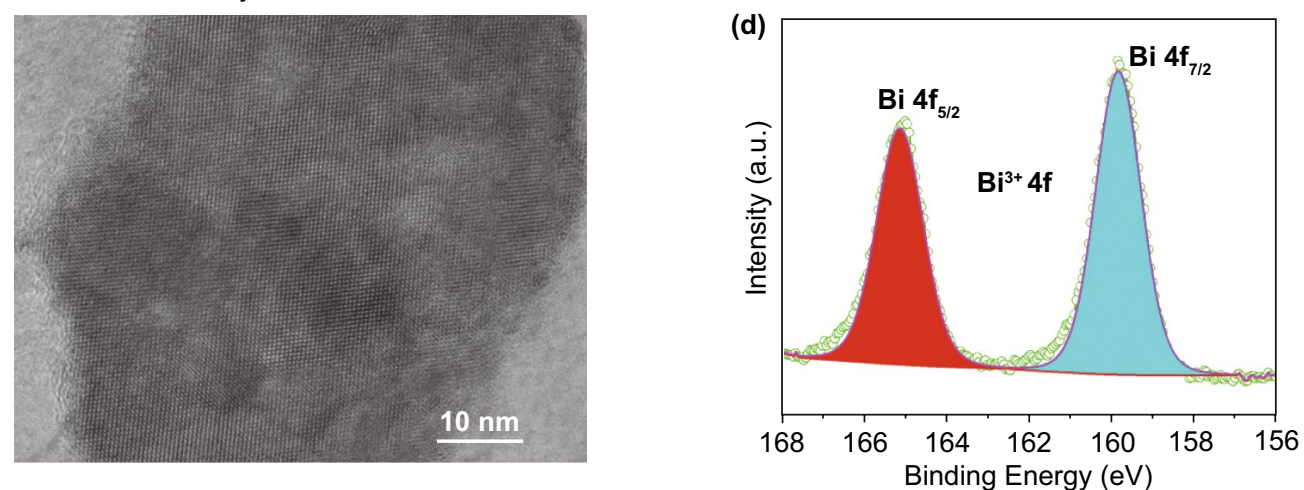

Fig. 4 a $\mathrm{FE}$ and $\mathrm{NH}_{3}$ yield rates of $\mathrm{Bi}_{2} \mathrm{O}_{3} / \mathrm{FEG}$ calculated after consecutive recycling electrolysis in $\mathrm{N}_{2}$-saturated $0.1 \mathrm{M} \mathrm{K}_{2} \mathrm{SO}_{4}$ solution at $-0.5 \mathrm{~V}$ (vs. RHE) for $2 \mathrm{~h}$. b $12 \mathrm{~h}$ durability test for $\mathrm{Bi}_{2} \mathrm{O}_{3} / \mathrm{FEG}$ toward ENRR at $-0.5 \mathrm{~V}$ (vs. RHE), inset: the corresponding $\mathrm{FE}$ and $\mathrm{NH}_{3}$ yield rate after durability test. $\mathbf{c}$ The HRTEM image of $\mathrm{Bi}_{2} \mathrm{O}_{3} / \mathrm{FEG}$ after ENRR. d Bi $4 f$ XPS spectrum of $\mathrm{Bi}_{2} \mathrm{O}_{3} / \mathrm{FEG}$ after ENRR

Acknowledgements This work was financially supported by Liaoning Revitalization Talents Program-Pan Deng Scholars (XLYC1802005), Liaoning BaiQianWan Talents Program, the National Science Fund of Liaoning Province for Excellent Young Scholars, Science and Technology Innovative Talents Support Program of Shenyang (RC180166), Australian Research Council (ARC) through Discovery Early Career Researcher Award (DE150101306) and Linkage Project (LP160100927), Faculty of Science Strategic Investment Funding of University of Newcastle, and CSIRO Newcastl Energy Centre.

Open Access This article is licensed under a Creative Commons Attribution 4.0 International License, which permits use, sharing, adaptation, distribution and reproduction in any medium or format, as long as you give appropriate credit to the original author(s) and the source, provide a link to the Creative Commons licence, and indicate if changes were made. The images or other third party material in this article are included in the article's Creative Commons licence, unless indicated otherwise in a credit line to the material. If material is not included in the article's Creative Commons licence and your intended use is not permitted by statutory regulation or exceeds the permitted use, you will need to obtain permission directly from the copyright holder. To view a copy of this licence, visit http://creativecommons.org/ licenses/by/4.0/.
Electronic supplementary material The online version of this article (https://doi.org/10.1007/s40820-020-00444-y) contains supplementary material, which is available to authorized users.

\section{References}

1. Z.Q. Wang, K. Zheng, S.L. Liu, Z.C. Dai, Y. Xu, X.N. Li, H.J. Wang, L. Wang, Electrocatalytic nitrogen reduction to ammonia by $\mathrm{Fe}_{2} \mathrm{O}_{3}$ nanorod array on carbon cloth. ACS Sustain. Chem. Eng. 13, 11754-11759 (2019). https://doi.org/10.1021/ acssuschemeng.9b01991

2. H. Cheng, L.X. Ding, G.F. Chen, L.L. Zhang, J. Xue, H.H. Wang, Nitrogen reduction reaction: molybdenum carbide nanodots enable efficient electrocatalytic nitrogen fixation under ambient conditions. Adv. Mater. 46, 1870350 (2018). https:// doi.org/10.1002/adma.201870350

3. V. Rosca, M. Duca, M.T. de Groot, M.T.M. Koper, Nitrogen cycle electrocatalysis. Chem. Rev. 6, 2209-2244 (2009). https ://doi.org/10.1021/cr8003696

4. C.D. Lv, C.S. Yan, G. Chen, Y. Ding, J.X. Sun, Y.S. Zhou, G.H. Yu, An amorphous noble-metal-free electrocatalyst that enables nitrogen fixation under ambient conditions. Angew. 
Chem. Int. Ed. 21, 6073-6076 (2018). https://doi.org/10.1002/ anie. 201801538

5. C.J.M. Van der Ham, M.T.M. Koper, D.G.H. Hetterscheid, Challenges in reduction of dinitrogen by proton and electron transfer. Chem. Soc. Rev. 15, 5183-5191 (2014). https://doi. org/10.1039/C4CS00085D

6. H.V. Doan, H.A. Hamzah, P.K. Prabhakaran, C. Petrillo, V.P. Ting, Hierarchical metal-organic frameworks with macroporosity: synthesis, achievements, and challenges. NanoMicro Lett. 11, 54 (2019). https://doi.org/10.1007/s4082 0-019-0286-9

7. H.J. Wang, H.J. Yu, Z.Q. Wang, Y.H. Li, Y. Xu, X.N. Li, H.R. Xue, L. Wang, Electrochemical fabrication of porous $\mathrm{Au}$ film on Ni foam for nitrogen reduction to ammonia. Small 6, 1804769 (2019). https://doi.org/10.1002/smll.201804769

8. G.F. Chen, X.R. Cao, S.Q. Wu, X.Y. Zeng, L.X. Ding, M. Zhu, H.H. Wang, Ammonia electrosynthesis with high selectivity under ambient conditions via a $\mathrm{Li}^{+}$incorporation strategy. J. Am. Chem. Soc. 29, 9771-9774 (2017). https://doi. org/10.1021/jacs.7b04393

9. M.M. Shi, D. Bao, B.R. Wulan, Y.H. Li, Y.F. Zhang, J.M. Yan, Q. Jiang, Au sub-nanoclusters on $\mathrm{TiO}_{2}$ toward highly efficient and selective electrocatalyst for $\mathrm{N}_{2}$ conversion to $\mathrm{NH}_{3}$ at ambient conditions. Adv. Mater. 17, 1606550 (2017). https://doi. org/10.1002/adma.201606550

10. M. Bat-Erdene, G.R. Xu, M. Batmunkh, A.S.R. Bati, J.J. White et al., Surface oxidized two-dimensional antimonene nanosheets for electrochemical ammonia synthesis under ambient conditions. J. Mater. Chem. A 9, 4735-4739 (2020). https://doi.org/10.1039/C9TA13485A

11. Y.F. Li, T.S. Li, X.J. Zhu, A.A. Alshehri, K.A. Alzahrani, S.Y. $\mathrm{Lu}$, X.P. Sun, $\mathrm{DyF}_{3}$ : an efficient electrocatalyst for $\mathrm{N}_{2}$ fixation to $\mathrm{NH}_{3}$ under ambient conditions. Chem. Asian J. 4, 487-489 (2020). https://doi.org/10.1002/asia.201901624

12. M.G. Wu, J.Q. Liao, L.X. Yu, R.T. Lv, P. Li et al., 2020 Roadmap on carbon materials for energy storage and conversion. Chem. Asian J. 15(7), 995-1013 (2020). https://doi. org/10.1002/asia.201901802

13. X.H. Guo, Y.P. Zhu, T.Y. Ma, Lowering reaction temperature: electrochemical ammonia synthesis by coupling various electrolytes and catalysts. J. Energy Chem. 6, 1107-1116 (2017). https://doi.org/10.1016/j.jechem.2017.09.012

14. C.Y. Ling, X.W. Bai, Y.X. Ouyang, A.J. Du, J.L. Wang, Single molybdenum atom anchored on $\mathrm{N}$-doped carbon as a promising electrocatalyst for nitrogen reduction into ammonia at ambient conditions. J. Phys. Chem. C 29, 16842-16847 (2018). https://doi.org/10.1021/acs.jpcc.8b05257

15. T.W. He, S.K. Matta, A.J. Du, Single tungsten atom supported on $\mathrm{N}$-doped graphyne as a high-performance electrocatalyst for nitrogen fixation under ambient conditions. Phys. Chem. Chem. Phys. 3, 1546-1551 (2019). https://doi.org/10.1039/ C8CP06978F

16. Y. Yao, H.J. Wang, X.Z. Yuan, H. Li, M.H. Shao, Electrochemical nitrogen reduction reaction on ruthenium. ACS Energy Lett. 6, 1336-1341 (2019). https://doi.org/10.1021/ acsenergylett.9b00699
17. H.J. Wang, Y.H. Li, C.J. Li, K. Deng, Z.Q. Wang, Y. Xu, X.N. Li, H.R. Xue, L. Wang, One-pot synthesis of bi-metallic PdRu tripods as an efficient catalyst for electrocatalytic nitrogen reduction to ammonia. J. Mater. Chem. A 2, 801-805 (2019). https://doi.org/10.1039/C8TA09482A

18. D.S. Yang, T. Chen, Z.J. Wang, Electrochemical reduction of aqueous nitrogen $\left(\mathrm{N}_{2}\right)$ at a low overpotential on (110)-oriented Mo nanofilm. J. Mater. Chem. A 36, 18967-18971 (2017). https://doi.org/10.1039/C7TA06139K

19. H.T. Du, X.X. Guo, R.M. Kong, F.L. Qu, $\mathrm{Cr}_{2} \mathrm{O}_{3}$ nanofiber: a high-performance electrocatalyst toward artificial $\mathrm{N}_{2}$ fixation to $\mathrm{NH}_{3}$ under ambient conditions. Chem. Commun. 91, 12848-12851 (2018). https://doi.org/10.1039/C8CC07186A

20. K. Chu, Y.P. Liu, J. Wang, H. Zhang, NiO nanodots on graphene for efficient electrochemical $\mathrm{N}_{2}$ reduction to $\mathrm{NH}_{3}$. ACS Appl. Energy Mater. 3, 2288-2295 (2019). https://doi. org/10.1021/acsaem.9b00102

21. T. Xu, D.W. Ma, C.B. Li, Q. Liu, S.Y. Lu, A.M. Asiri, C. Yang, X.P. Sun, Ambient electrochemical $\mathrm{NH}_{3}$ synthesis from $\mathrm{N}_{2}$ and water enabled by $\mathrm{ZrO}_{2}$ nanoparticles. Chem. Commun. 25, 3673-3676 (2020). https://doi.org/10.1039/C9CC10087C

22. X.H. Li, X. Ren, X.J. Liu, J.X. Zhao, X. Sun et al., A MoS nanosheet-reduced graphene oxide hybrid: an efficient electrocatalyst for electrocatalytic $\mathrm{N}_{2}$ reduction to $\mathrm{NH}_{3}$ under ambient conditions. J. Mater. Chem. A 6, 2524-2528 (2019). https:// doi.org/10.1039/C8TA10433F

23. P.X. Li, W.Z. Fu, P.Y. Zhuang, Y.D. Cao, C. Tang et al., Amorphous $\mathrm{Sn}$ /crystalline $\mathrm{SnS}_{2}$ nanosheets via in situ electrochemical reduction methodology for highly efficient ambient $\mathrm{N}_{2}$ fixation. Small 40, 1902535 (2019). https://doi.org/10.1002/ smll.201902535

24. H.Y. Jin, L.Q. Li, X. Liu, C. Tang, W.J. Xu et al., Nitrogen vacancies on $2 \mathrm{D}$ layered $\mathrm{W}_{2} \mathrm{~N}_{3}$ : a stable and efficient active site for nitrogen reduction reaction. Adv. Mater. 32, 1902709 (2019). https://doi.org/10.1002/adma.201902709

25. G.F. Chen, S.Y. Ren, L.L. Zhang, H. Cheng, Y.R. Luo, K.H. Zhu, L.X. Ding, H.H. Wang, Nitrogen reduction reactions: advances in electrocatalytic $\mathrm{N}_{2}$ reduction-strategies to tackle the selectivity challenge. Small Methods 6, 1970016 (2019). https://doi.org/10.1002/smtd.201970016

26. J.H. Montoya, C. Tsai, A. Vojvodic, J.K. Nørskov, The challenge of electrochemical ammonia synthesis: a new perspective on the role of nitrogen scaling relations. Chemsuschem 13, 2180-2186 (2015). https://doi.org/10.1002/cssc.20150 0322

27. Z. Wang, F. Gong, L. Zhang, R. Wang, L. Ji et al., Electrocatalytic hydrogenation of $\mathrm{N}_{2}$ to $\mathrm{NH}_{3}$ by $\mathrm{MnO}$ : experimental and theoretical investigations. Adv. Sci. 1, 1801182 (2019). https ://doi.org/10.1002/advs.201801182

28. Y. Wang, M.M. Shi, D. Bao, F.L. Meng, Q. Zhang et al., Generating defect-rich bismuth for enhancing the rate of nitrogen electroreduction to ammonia. Angew. Chem. Int. Ed. 28, 9464-9469 (2019). https://doi.org/10.1002/anie.201903 969

29. Y.C. Hao, Y. Guo, L.W. Chen, M. Shu, X.Y. Wang et al., Promoting nitrogen electroreduction to ammonia with bismuth 
nanocrystals and potassium cations in water. Nat. Catal. 5, 448-456 (2019). https://doi.org/10.1038/s41929-019-0241-7

30. F.Y. Wang, X. Lv, X.J. Zhu, J. Du, S.Y. Lu et al., Bi nanodendrites for efficient electrocatalytic $\mathrm{N}_{2}$ fixation to $\mathrm{NH}_{3}$ under ambient conditions. Chem. Commun. 14, 2107-2110 (2020). https://doi.org/10.1039/C9CC09803H

31. L.Q. Li, C. Tang, B.Q. Xia, H.Y. Jin, Y. Zheng, S.Z. Qiao, Two-dimensional mosaic bismuth nanosheets for highly selective ambient electrocatalytic nitrogen reduction. ACS Catal. 4, 2902-2908 (2019). https://doi.org/10.1021/acscatal.9b00366

32. Y. Peng, M. Yan, Q.G. Chen, C.M. Fan, H.Y. Zhou, A.W. $\mathrm{Xu}$, Novel one-dimensional $\mathrm{Bi}_{2} \mathrm{O}_{3}-\mathrm{Bi}_{2} \mathrm{WO}_{6} \mathrm{p}-\mathrm{n}$ hierarchical heterojunction with enhanced photocatalytic activity. J. Mater. Chem. A 22, 8517-8524 (2014). https://doi.org/10.1039/ C4TA00274A

33. H.J. Lu, Q. Hao, T. Chen, L.H. Zhang, D.M. Chen, C. Ma, W.Q. Yao, Y.F. Zhu, A high-performance $\mathrm{Bi}_{2} \mathrm{O}_{3} / \mathrm{Bi}_{2} \mathrm{SiO}_{5}$ $\mathrm{p}-\mathrm{n}$ heterojunction photocatalyst induced by phase transition of $\mathrm{Bi}_{2} \mathrm{O}_{3}$. Appl. Catal. B-Environ. (2018). https://doi. org/10.1016/j.apcatb.2018.05.069

34. S. Sanna, V. Esposito, J.W. Andreasen, J. Hjelm, W. Zhang et al., Enhancement of the chemical stability in confined $\delta-\mathrm{Bi}_{2} \mathrm{O}_{3}$. Nat. Mater. 5, 500-504 (2015). https://doi. org/10.1038/nmat4266

35. Y. Song, X. Cai, X.X. Xu, X.X. Liu, Integration of nickelcobalt double hydroxide nanosheets and polypyrrole films with functionalized partially exfoliated graphite for asymmetric supercapacitors with improved rate capability. J. Mater. Chem. A 28, 14712-14720 (2015). https://doi.org/10.1039/C5TA0 $2810 \mathrm{H}$

36. J.H. Cao, K.X. Wang, J.Y. Chen, C.J. Lei, B. Yang, Z.J. Li, L.C. Lei, Y. Hou, K. Ostrikov, Nitrogen-doped carbon-encased bimetallic selenide for high-performance water electrolysis. Nano-Micro Lett. 11, 67 (2019). https://doi.org/10.1007/s4082 0-019-0299-4

37. Y.L. Yang, Y. Tang, H.M. Jiang, Y.M. Chen, P.Y. Wan et al., 2020 Roadmap on gas-involved photo- and electro-catalysis. Chin. Chem. Lett. 12, 2089-2109 (2019). https://doi. org/10.1016/j.cclet.2019.10.041

38. Y.W. Cheng, H.B. Zhang, C.V. Varanasi, J. Liu, Improving the performance of cobalt-nickel hydroxide-based self-supporting electrodes for supercapacitors using accumulative approaches. Energy Environ. Sci. 11, 3314-3321 (2013). https://doi. org/10.1039/C3EE41143E

39. D. Chen, L.H. Tang, J.H. Li, Graphene-based materials in electrochemistry. Chem. Soc. Rev. 8, 3157-3180 (2010). https ://doi.org/10.1039/B923596E
40. S. Mukherjee, Z. Ren, G. Singh, Beyond graphene anode materials for emerging metal ion batteries and supercapacitors. Nano-Micro Lett. 10, 70 (2018). https://doi.org/10.1007/ s40820-018-0224-2

41. Y. Sun, W. Zhang, J. Tong, Y. Zhang, S.Y. Wu et al., Significant enhancement of visible light photocatalytic activity of the hybrid $\mathrm{B}_{12}$-PIL/rGO in the presence of $\mathrm{Ru}(\mathrm{bpy})_{3}^{2+}$ for DDT dehalogenation. RSC Adv. 31, 19197-19204 (2017). https:// doi.org/10.1039/C7RA02062G

42. Y.L. Yang, M.G. Wu, X.W. Zhu, H. Xu, S. Ma et al., 2020 Roadmap on two-dimensional nanomaterials for environmental catalysis. Chin. Chem. Lett. 12, 2065-2088 (2019). https:// doi.org/10.1016/j.cclet.2019.11.001

43. Y.B. Xu, Y. Song, Z.G. Zhang, A binder-free fluidizable Mo/ HZSM-5 catalyst for non-oxidative methane dehydroaromatization in a dual circulating fluidized bed reactor system. Catal. Today (2017). https://doi.org/10.1016/j.cattod.2016.03.037

44. C.H. Jiang, Z.X. Ye, H.T. Ye, Z.M. Zou, $\mathrm{Li}_{4} \mathrm{Ti}_{5} \mathrm{O}_{12} @$ carbon cloth composite with improved mass loading achieved by a hierarchical polypyrrole interlayer assisted hydrothermal process for robust free-standing sodium storage. Appl. Surf. Sci. (2020). https://doi.org/10.1016/j.apsusc.2019.144464

45. J.C. Liu, H. Li, M. Batmunkh, X. Xiao, Y. Sun, Q. Zhao, X. Liu, Z.H. Huang, T.Y. Ma, Structural engineering to maintain the superior capacitance of molybdenum oxides at ultrahigh mass loadings. J. Mater. Chem. A 41, 23941-23948 (2019). https://doi.org/10.1039/C9TA04835A

46. B. Yu, H. Li, J. White, S. Donne, J.B. Yi et al., Tuning the catalytic preference of ruthenium catalysts for nitrogen reduction by atomic dispersion. Adv. Funct. Mater. 6, 1905665 (2020). https://doi.org/10.1002/adfm.201905665

47. S.B. Liu, X.F. Lu, J. Xiao, X. Wang, X.W. Lou, $\mathrm{Bi}_{2} \mathrm{O}_{3}$ nanosheets grown on multi-channel carbon matrix to catalyze efficient $\mathrm{CO}_{2}$ electroreduction to HCOOH. Angew. Chem. Int. Ed. 39, 1382813833 (2019). https://doi.org/10.1002/anie.201907674

48. Q. Qin, M. Oschatz, Overcoming chemical inertness under ambient conditions: a critical view on recent developments in ammonia synthesis via electrochemical $\mathrm{N}_{2}$ reduction by asking five questions. ChemElectroChem 4, 878-889 (2020). https:// doi.org/10.1002/celc. 201901970

49. D. Bao, Q. Zhang, F.L. Meng, H.X. Zhong, M.M. Shi et al., Electrochemical reduction of $\mathrm{N}_{2}$ under ambient conditions for artificial $\mathrm{N}_{2}$ fixation and renewable energy storage using $\mathrm{N}_{2} / \mathrm{NH}_{3}$ cycle. Adv. Mater. 3, 1604799 (2017). https://doi. org/10.1002/adma.201604799 